\title{
Fairness and Incentive Contracting Based on the Performance Budget: Testing Experiment on Referent Cognition Theory
}

\author{
Suharli Manoma \\ Department of Economic Science Universitas Muhammadiyah Maluku Utara, KH. Ahmad Dahlan 100 Ternate City, Indonesia
}

\begin{abstract}
Based on the referential cognitive theory, this study examines the effects of fairness and incentive for individual performance in a not participative budgeting setting. An experimental design $2 \times 2$ between subject was conducted. Participants are as many as 88 students of the accounting program. Two way anova analysis is used to investigate hypothesis. The result shows as predicted by referent cognition theory. Performance was lowest when an unfair budget target assigned using an unfair budgeting process. When the budget target assigned was fair, the fairness or unfairness of the budgeting process had no effect on performance. When an unfair budget target was determined using a fair budgeting process, performance was not significantly different from the performance of the subjects assigned fair budget targets.
\end{abstract}

Keywords: Fairness; Referent Cognitions; Budgeting, Incentive Contracting.

\section{Introduction}

The result shows referent cognition as predicted by theory. Performance was an unfair Lowest when using an assigned budget target unfair budgeting process. When the assigned budget targets were fair, the fairness or unfairness of the budgeting process had no effect on performance. When an unfair budget targets were determined using a fair budgeting process, performance was not Significantly different from the performance of the subjects assigned fair budget targets.

Every organization expects that the budget has been set can be achieved. But the targeting of the budget and its adoption process are two important factors that must be considered. In general, someone will compare the budget set for him by the other party equivalent. This gives rise to the perception of fairness on the target as well as its determination process. Thus the perception of fairness was a disincentive to perform well. The individual's perception of fairness or justice in both the target and the process becomes the motivation for individuals to achieve a set budget (Libby 1999; Wetzel 1999; Lindquist 1995). One theory regarding the fairness test is a theory referent cognitions. According to the theory referent cognitions, interactions between fairness to the budget targets and fairness in the process of determining the budget targets is a combination that can lead to motivation in achieving budget.

According to Folger (1986), when budget targets are determined in a fair, then the information on the determination process is not important in motivating the achievement of targets. On the other hand, when the budget targets set by the unfair, then the individual will try to find information about how the process of determining the budget targets. If it is produced from a process that is not fair, then people began to feel very angry, so are less motivated to achieve budget targets (Cropanzano and Folger 1991).

This study aims to examine how the interaction between perceptions of fairness and incentives promised in motivating individuals to perform in achieving budget targets. Through the experimental method, fairness against budget targets manipulated at the fair if the target can be achieved (Attainable) and unfair if the target cannot be achieved (unattainable). Fairness in the process of achieving the target includes two elements, namely the degree to which the budget targets compared with the target of another party (referent), and fairness in the process of determining the budget itself. In this study, the manipulation of fairness to the process of determining the budget targets set for the other parties are equal (fair) and higher (unfair) than that set for himself.

The results of this research may be a consideration for top managers in allocating resources and set a budget. When an organization has limited to a participatory budget process, this will lead to a sense of injustice because organizations are not always able to meet what managers need division. In organizations with non-participatory budget, the concept of fairness, both in setting budget targets and the determination process, provide significant impact in an effort to motivate manager division to give their best performance.

\section{Literature Review and Hypothesis}

Bazerman (1994) argues that human beings are very concerned with fairness to influence decisions and their lives. Everything will direct judgment about what someone thought about a sense of injustice. Fairness refers to the understanding of how cognitive processes shaping feelings of anger, jealousy and inefficiency in. Fairness can be viewed from two elements of the outcomes and the process. Kahneman, Knetsch and Thaler (1986) examined the fairness in setting the experiments conducted on supply and demand. The study showed that considerations of fairness may dominate rational choice in making economic decisions. Lindquist study (1995) showed that a fair process is defined through subordinate participation in setting the budget targetsetting and other aspects of the budgeting process was 


\section{International Journal of Science and Research (IJSR) \\ ISSN (Online): 2319-7064}

Index Copernicus Value (2013): 6.14 | Impact Factor (2015): 6.391

manipulated. Shields and Shields (1998) examine the effect of participation in the budgeting at several different outcomes, including performance and the creation of budgetary slack. Bruckner and Wiesenfeld (1996) review of 45 studies on the individual's responses to the resource allocation decisions. The study connects the perceptions of the fairness of the results of the allocation process, the allocation process itself and the breadth of a wide variety of psychological outcomes, including commitment, trust, job satisfaction and turnover intention. The review suspected the interaction effect consistent with theoretical predictions referent cognition.

The study used projections based on the theory of cognition referent that, comparisons referential on the allocation of outcome and process in motivating fairness judgments. Bazerman (1994) suggested that fairness can be seen by comparing the outcomes that we receive with what it should be accepted. Another way is to compare the outcomes that we received with acceptable outcomes that other party equivalent (referent).

According to the theory of cognition referent, when individuals receive results that are not fair, their judgment becomes attached to the referent or other parties (Folger 1986). Therefore, one would compare the outcomes they receive the referent outcome, such outcomes were due to receive or received by others with equivalent position, with relatively similar input to input other parties (Adam 1965). If the referent outcome indicates an unsatisfactory results received by a person and the perceived outcome should be accepted together with other parties, then this will lead to anger and jealousy.

This study sought to test the predictions of the theory referent cognitions in the context of accounting in budget performance assessment with incentive-based contract. In these settings, the outcome of the allocation process is defined as the budget targets to be achieved by the individual and the process of allocation refers to the process used in determining the budget targets.

Lindquist (1995) examined the outcome of fair and unfair budget targets and the target setting process from the perspective of the theory of cognition referent. The result predicts the combination of subordinate voice (no influence) and vote (with effect) in the budgeting process will produce higher performance than just voice, vote alone or no input when the target budget is accepted. Second, Lindquist (1995) predicts voice alone will produce a high performance compared to voice or vote only when the target of unfair budget accepted. These results failed to support the main predictions or interactive effects fairness to budget targets and forms of participation budgeting on performance. Based on previous studies, analysis Brockner and Wiesenfeld (1996), and the predictions of the theory referent cognitions about the reaction of the individual against the allocation decision then built the following hypothesis:

1. Determination of unfair budget targets and unfair budget process will result in lower performance. To complete the referent cognitive theory, put forward the theory that goal alternative theory. This theory suggests that if a goal cannot be achieved (unattainable), then it will not be accepted by the subordinate (Locke 1982). Thus, unattainable goals will have no influence on the subordinate, it will decrease the motivation to perform (Locke 1982). Based on the goal theory, the performance drops when the budget targets unfair (unattainable) than when the budget targets for (attainment). In this case the individual ignores the fairness or unfairness in the process of determining the budget targets. Thus the following hypothesis is proposed:

2. Without influenced by the budget process, the determination of unfair budget targets will result in lower performance than its fair budget targets. Folger (1986) tested the referential cognitive theory by showing a negative reaction from a combination of unfair outcome resulting from a process that is unfair (Folger 1986). Although Bruckner and Wiesenfeld (1996), found a positive effect of fair process in the individual reactions to unfair outcomes. These results cannot be predicted by the theory of cognition referent. Cropanzano and Folger (1989) extend the theory of cognition referent to test the effect of unfair outcome as a result of a fair procedure. When the resulting unfair outcome of the procedure fair, people will look at outcomes as an anomaly (Folger 1986) or attributes it as being against any organization (Cropanzano and Folger 1991). Cropanzano and Folger (1989) found when unfair outcome resulting from the procedure fair, many individuals do not express the anger against it. Someone will remain motivated to perform and is not affected by the outcome that is not fair. Thus, the following hypothesis:

3. When unfair budget targets determined based on fair budget process, it will produce a high performance compared to when unfair budget targets determined through the budget process unfair.

\section{Methodology}

Participants involved in research experiments are 88 students majoring in accounting executive class private university in the city of Ternate. Executive class accounting students selected on the basis that most of them have worked and have experience in the process of achieving employment targets. Thus, the researchers assume the respondents are represented in illustrative experiment cases assigned to them. Participants are formed into four treatment conditions. Each participant gets one treatment conditions. Work assignment experiments carried out at random (randomly assigned) on two conditions, namely treatment Determination of Budget Target (attainability and Unattainability) and Budget Process (Equal and Higher). Random placement (random assignment) into groups necessary to make these groups can be compared (Cooper and Schinedler 2001). Sekaran (2000) also suggested that randomization will guarantee each group can be compared with each other.

The whole series of experiments takes approximately 30 minutes at the start of the experiment and charging duty explanation demographics of respondents, followed by exercises of task completion translate the words for 10 


\section{International Journal of Science and Research (IJSR) \\ ISSN (Online): 2319-7064}

Index Copernicus Value (2013): 6.14 | Impact Factor (2015): 6.391

minutes and finally completing the individual tasks in achieving the budget targets for 20 minutes. Of the 88 respondents, 5 respondents did not complete the task on time and do not understand the manipulation experiments on budget targets and budget process. Therefore, all the research data that can be processed totaling 83 subjects. This research uses experimental design to investigate the hypothesis. Experiments designed to study two by two (2x2) factorial design and the between-subject. In this case the design using the perception of fairness is for the determination of the target budget and budget process. Budget targets are considered fair when people feel able to achieve the set targets. While the budget process is considered fair when people are given more targets together with others equivalent (referent) and the decision will be taken through the initial consideration of the individual's ability to achieve the target. Researchers manipulated two levels of budget targets a budget that is fair to the attainability manipulated targets (achievable), while the budget targets unfair manipulated by unattainability (difficult to achieve). For fairness in the budget process, researchers manipulated at two levels, namely equal and higher when compared to the target set for the other party (referent).

Table 1: Design 2x2 between-subject experiments

\begin{tabular}{|c|c|c|}
\hline \multirow{2}{*}{ Fairness of Budget Target } & \multicolumn{2}{|c|}{ Fairness of Budget Process } \\
\cline { 2 - 3 } & Equal (Fair) & High (Unfair) \\
\hline Attainability (Fair) & $\mathrm{A}$ & $\mathrm{B}$ \\
$\mathrm{N}=20$ & $\mathrm{~N}=20$ \\
\hline Unattainability (Unfair) & $\mathrm{C}$ & $\mathrm{D}$ \\
& $\mathrm{N}=23$ & $\mathrm{~N}=25$ \\
\hline
\end{tabular}

In condition $\mathrm{A}$, participants get fair treatment budget targets (attainable) and a fair budget process (equal than the referent). Condition B is formed with a fair budget targets (attainable) and unfair budget process (higher than the referent). While on the condition $\mathrm{C}$, participants gain unfair budget targets (unattainable) and a fair budget process (equal to the referent). In conditions $\mathrm{D}$, participants formed with unfair budget targets (unattainable) and unfair budget process (higher than the referent).

The whole series of experimental tasks can be completed in less than thirty minutes. As a first step, participants were asked to fill out demographic data. Then, guided the researchers, participants were asked to perform exercises translate symbols into the alphabet to form words Indonesian. In this exercise, participants were given the key to the alphabet, which translates as can be seen in figure 1. Two tasks such experiments spent about 10 minutes.

After completing the first task and the second, then the respondent will learn and understand the assignment of the third which is the core of the assignment experiments. At this stage the respondents were asked to read the illustrative case considers itself with the existing characters in the illustrative case. Presented case is a manipulation of the good condition of fairness in the determination of the target budget and budget process. Completion of the third task given time for 20 minutes. Manuscript experiments presented in two stages. The first phase as follows: each scenario pack contains introductory session, which respondents self-perception as a team member translators of accounting at a company issuer. At this stage the respondents were asked to do the exercises translate the words symbolized into words in alphabetical Indonesian. The next phase, respondents receive their respective treatments of the four conditions were manipulated. In fairness treatments for a fair budget target, respondents were given a target to translate the number of words that can be achieved (attainable). While the unfair conditions of budget targets, respondents were given the number of words that are more difficult to achieve so it is assumed (unattainable). As for treatment budget process is comparing the number of words to be translated by the respondents, the same amount (equal) or higher (higher) than the other team. This instrument develops instruments developed by Theresa Libby (2001).

To manipulate the achievement of performance conditions based budget with incentive contracting, research illustrates that each member is able to achieve the target of translating the word correctly then it will be given a certain bonus. In addition, team members will also get an added bonus to every word that is able to translate correctly. It is expected to motivate people to perform well in achieving budget targets even though the organization is not able to fulfill the concept of fairness.

\begin{tabular}{|c|c|c|c|c|c|c|c|c|c|c|c|c|}
\hline $\mathbf{A}$ & B & (c) & 3 & $€$ & $\mathbf{P}$ & $\tilde{\varepsilon}$ & $\psi$ & $\ddot{\mathrm{e}}$ & 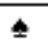 & $\Phi$ & $£$ & $\boldsymbol{\mu}$ \\
\hline $\mathbf{A}$ & B & $\mathbf{C}$ & D & $\mathbf{E}$ & $\mathbf{F}$ & $\mathbf{G}$ & $\mathbf{H}$ & I & $\mathbf{J}$ & $\mathbf{K}$ & $\mathbf{L}$ & $\mathbf{M}$ \\
\hline$\Omega$ & 9 & $\mathrm{~T}$ & $\star$ & . & 8 & $x$ & 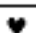 & $\bullet$ & $\mathbb{L}$ & $\pi$ & \pm & \pm \\
\hline $\mathbf{N}$ & $\mathbf{O}$ & $\mathbf{P}$ & $\mathbf{Q}$ & $\mathbf{R}$ & $\mathrm{S}$ & $\mathbf{T}$ & $\overline{\mathrm{U}}$ & $\mathbf{V}$ & $\mathbf{W}$ & $\mathbf{X}$ & $\mathbf{Y}$ & $\mathbf{Z}$ \\
\hline
\end{tabular}

Example:

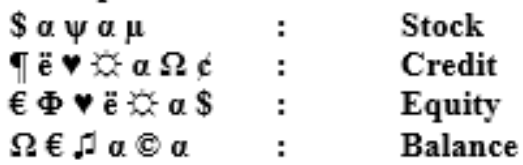

Figure 1: Key to Symbols and Words with Meaning Example

\section{Dependent Variable}

The dependent variable is the performance of the subjects in the experimental task completion. Performance study subjects assessed after the respondent manipulated and explained about the reward they will get. The basis for determining the budget targets is the average ability of the participants in the translation of words in the previous exercise. Item performance is measured by the ability to translate properly the subject of a number of words that are presented. When the subject was able to complete a number of specified targets or the subjects considered to be performing well, and vice versa.

\section{Respondent demographics}

Respondents in this study were 88 students majoring in accounting executive class private college. Of the 88 instruments were granted, 5 instruments cannot be used because the respondents did not understand the experimental manipulation. Asked demographic variables were age, gender, work experience. The average age of respondents was 28 years, the number of male respondents, 64\% and 


\section{International Journal of Science and Research (IJSR) \\ ISSN (Online): 2319-7064}

Index Copernicus Value (2013): 6.14 | Impact Factor (2015): 6.391

women $36 \%$. ANOVA was used to test whether there are significant differences among the four conditions established treatments. As verification that randomization generated in a variety of groups with measurement results almost the same, so that the demographic characteristics of the four groups can be compared.

\section{Results and Discussion}

The questionnaire contains two items statement to test the perception of fairness. In this case the statement submitted to the fairness test manipulation at budget targets and budget process. Answer each item are averaged together on a 7 points scale for each manipulation. Respondents were asked to respond on a scale of 1 for strongly disagree with 7 to strongly agree. To test the manipulation of fairness on budget targets, the respondents gave approval for the statement: "Budget targets set for my number 10 (20) is fair?". Statistically significant differences between the two treatments were set up for the perception of fairness budget targets. Fair budget targets defined as attainable whereas unfair budget targets defined as unattainable. Statistical analysis showed differences in the perception of manipulation of the budget targets set $(\mathrm{F}=141.737$; $\mathrm{p}=$ 0.000 ). Mean perceptions indicate a fair level at the time of budget targets set attainable than unattainable.

To test the manipulation of the budget process, the subjects were asked to provide a response to the statement: "The process is carried out to determine the target budget for me is fair?". Budget process fairness is measured by a comparison with the budget set referent. Fair budget process manipulated by "equal" whereas unfair measured by "higher" than the referent. The analysis showed differences in the perception of fairness is formed of manipulation treatments $(\mathrm{F}=0.770$; $\mathrm{p}=$ 0.038). Mean perceptions indicate a fair level during the budget process is set equal than higher.

Table 2. Perception of Fairness Testing

\begin{tabular}{|c|c|c|c|c|}
\hline \multirow[b]{2}{*}{$\begin{array}{l}\text { Fairness } \\
\text { Perseption }\end{array}$} & \multicolumn{2}{|c|}{ Mean Condition } & \multirow[b]{2}{*}{ F- Ratio } & \multirow[b]{2}{*}{$\begin{array}{c}p- \\
\text { value }\end{array}$} \\
\hline & $\begin{array}{c}\text { Fair } \\
\text { (Attainability } \\
\text { /Equal) } \\
\end{array}$ & $\begin{array}{c}\text { Unfair } \\
\text { (Unattainability/ } \\
\text { Higher) }\end{array}$ & & \\
\hline $\begin{array}{c}\text { Fairness of Budget } \\
\text { Target } \\
\end{array}$ & 5,55 & 2,58 & 141,737 & 0,000 \\
\hline $\begin{array}{c}\text { Fairness of Budget } \\
\text { Process } \\
\end{array}$ & 6,19 & 3,83 & 0,770 & 0,038 \\
\hline
\end{tabular}

Performance is measured through the number of words successfully translated in the assignment experiment. The ability of the subject is measured by the number of words successfully translated into practice sessions prior to the actual experiments with the task of manipulation and a description of the incentive contract. Descriptive statistics for performance within each experimental condition are presented in Table 3.

Hypothesis 1 (H1) suspects that in conditions of unfair budget targets and unfair budget process, then the resulting performance will be low. Mean in Table 3 shows that in these conditions the average performance of the resulting respondents is lower than in other circumstances (13.52). A significant interaction between the target and the process $(\mathrm{F}=$ 8.029 ) and $p=0.006$ ) providing support for $\mathrm{H} 1$. The results predict that the performance can be negatively affected only if the budget targets and budget process are both unfair (see Table 4 Panel A).

Table 3: Average Performance in Four Conditions Experiment

\begin{tabular}{|c|c|c|}
\hline Fairness of & \multicolumn{2}{|c|}{ Fairness of Budget Process } \\
\cline { 2 - 3 } Budget Target & Equal (Fair) & Higher (Unfair) \\
\hline Attainable (Fair) & 15,95 & 16,10 \\
\hline Unattainable (Unfair) & 15,30 & 13,52 \\
\hline
\end{tabular}

Furthermore Hypothesis 2 predicts unfair budget targets result in poor performance compared to fair budget targets, regardless of how the budget process is determined targets. While, to the hypothesis 2 (H2), the result of ANOVA analysis is presented in Table 4 (Panel A) shows the budget target of fairness is significant, F (61.001) and p (0.000). The results of this analysis indicate that the fairness in the determination of the target will have a significant impact on the performance of both the fair and the unfair conditions of the budget process. Analysis of the budget process, fairness indicates $F(2.484)$ and $p(0.119)$. The analysis indicates that the process is fair or unfair is not significantly different in performance achievement. This supports the prediction that was built in the second hypothesis which suggests that when unfair budget targets specified, then the performance will be lower than when in a state fair budget targets without regard to fairness in the process of determining the target. On the average performance of the resulting, respondents in the cell condition $\mathrm{AB}$ have higher performance than the cell condition CD. Hypothesis 3 (H3) predicts the performance of subjects in conditions of unfair budget target / fair budget process is higher than the performance of subjects who are in conditions of unfair budget targets / unfair process. The average performance of the subjects in a group of fair process is higher than (15.30) compared to the average performance of the subjects in the group of unfair processes (13.52). Thus the hypothesis is supported by the results of a comparison of three men that indicates that when the target is received by respondents considered unfair, but through a fair process, the performance is higher than when it is known that the process of determining the target of unfair.

Table 4: Analysis result of Variance Panel A: ANOVA result: Performance

\begin{tabular}{|c|c|c|c|}
\hline \multicolumn{5}{|c|}{ Panel A: ANOVA result: Performance } \\
\hline Variance Sources & Df & F-Ratio & p-value \\
\hline Fairness of Budget Target & 1 & 61,001 & 0,000 \\
\hline Fairness of Budget Process & 1 & 2,484 & 0,119 \\
\hline $\begin{array}{l}\text { Interaction Term (Budget } \\
\text { Target * Budget Process) }\end{array}$ & 1 & 8,029 & 0,006 \\
\hline \multicolumn{4}{|c|}{ Panel B: Mean Performance } \\
\hline Budget Target / Budget Process & Mean & Std. dev. \\
\hline Attainability / Equal ( Cell A) & 15,95 & 2,50 \\
\hline Attainability / Higher ( Cell B) & 16,10 & 2,26 \\
\hline Unattainability / Equal (Cell C) & 15,30 & 3,68 \\
\hline Unattainability / Higher (cell D) & 13,52 & 3,89 \\
\hline \multicolumn{4}{|c}{} \\
\hline
\end{tabular}

Research in the field of fairness previously shown that participatory decision-making can create a perception that both the target and fair process. This could lead to the 


\section{International Journal of Science and Research (IJSR) \\ ISSN (Online): 2319-7064}

Index Copernicus Value (2013): 6.14 | Impact Factor (2015): 6.391

desired attitudes and behavior of managers in the division of decentralized organizations. However, their involvement to participate fully not always possible due to the limitations of the organization's resources. Was not involved in the decision subordinate organizational resource allocation often cause unwanted behavior. This study examines the effect of fairness in the determination of budget targets and its determination process. By using predictive theory referent cognition, the results of this study indicate that a person who receives unfair unfair budget targets and budget process will result in lower performance. Performance in these conditions is lower compared with individuals who received unfair budget targets, but through a fair budget process. While individual performance targets are determined in a fair budget, then the performance will not differ significantly, although the budget setting process specified target in a fair or unfair.

Based on the view referent theory of cognition, motivational influence can be generated not only through involvement in the budgeting process, but also through actions to communicate with the treatment of a person related to others in the group. Incentive contracting offered by the organization can motivate performance despite the targeting process is not fair. Incentive contract can be a factor that may explain the performance difference between the experimental group.

\section{Conclusion}

The Tested of hypothesis 1 (H1) that under conditions of target setting budgets that are fair and determination process is not fair, then the resulting performance will be low. A significant interaction between the target and the support $\mathrm{H} 1$ predict that performance can be adversely affected only if the budget targets and budget process are both unfair.

Furthermore, the analysis results support the hypothesis 2 predicts unfair budget targets result in poor performance compared to fair budget targets, regardless of how the budget process is determined targets. Hypothesis 3 predicts the performance of subjects in conditions of unfair budget target / fair budget process is higher than the performance of subjects who are in conditions of unfair budget targets / unfair process. The results of the analysis support the hypothesis 3 through comparative results mean that indicates that when the target is received by respondents considered unfair, but through a fair process, the performance is higher than when it is known that the process of determining the target unfair.

Research on fairness is still very wide. Further research may be able to explore other aspects of fairness that may affect attitudes and behavior. The addition of other variables that can eliminate dysfunctional behaviors as a result of the non participative decision still needed. The use of more complex scenarios and realistic as well as the use of sample which is really a good step in testing future. The results of this study have limitations inherent in this study. First, the experimental method has limitations in external validity, inability to generalize the results of experimental research thoroughly conclusions. Secondly, the limited time of execution of experimental tasks for the participants.

\section{References}

[1] Adams, J.S. 1965. Inequity in Social Exchange. In: L. Berkowitz (Ed). Advances in Experimental Social Psychology Vol.2, Edited by. L. Berkowitz. San Diego. CA: Academic Press.

[2] Brockner, J., and B.M. Wiesenfeld. 1996. An Integrative Framework For Explaining Reactions to Decision: Interactive Effects of Outcomes and Procedures. Psychological Bulleting 120 (2): 189-208.

[3] Bazerman, Max H. 1994. Judgment in Managerial Decision Making. John Wiley \& Sons, Inc. Singapore. Third Edition.

[4] Cropanzano, R., and R. Folger. 1989. Referent Cognitions and Task Decision Autonomy: Beyond Equity Theory. Journal of Appliend Psychology 74: 293-299.

[5] Cropanzano, R., and R. Folger. 1991. Procedural Justice and Worker Motivation. In Motivation and Work Behavior. Edited by R. M. Staw, and L.W. Porter, 131-143. New York, NY: McGraw-Hill.

[6] Folger, R., D. Rosenfeld, and T. Robinson. 1983. Relative Deprivation and Procedural Justification. Journal of Personality and Social Psychology 45: 268273.

[7] Folger, R. 1986. Rethinking Equity Theory: A Referent Cognitions Model. In Justice in Social Relations. Edited by H.W. Bierhoff, R.L. Cohen, and J. Greenberg. 145-162. New York. NY: Plenum Press.

[8] Hopwood, A. 1972. An Empirical Study of The Role of Accounting Data in Performance Evaluation. Journal of Accounting Research 10 (Supplement): 156-182.

[9] Kahneman, D., Knetsch, J.L., and Thaler, R. 1986. Fairness as a Constraint on Profit Seeking: Entitlements in The Market. American Economic Review 76, 728741.

[10] Libby, T. 1999. The Influence of Voice and Explanation on Performance in a Participative Budgeting Setting. Accounting, Organizations and Society 24: 125-137.

[11] Lindquist, T.M. 1995. Fairness as An Antecedent to Participative Budgeting: Examining the Effects of Distributive Justice, Procedural Justice and Referent Cognitions on Satisfaction and Performance. Journal of Management Accounting Research. Vol. 7: 122-147.

[12] Locke, E. A. 1982. Relation of Goal Level to Performance With a Short Work Period and Multiple Goal Levels. Journal of Applied Psychology 67: 512514.

[13] Merchant, K.A. 1998. Modern Management Control Systems. Upper Saddle River. NJ: Prentice Hall. 